\title{
Modified Penman-Monteith equation for monitoring evapotranspiration of wheat crop: relationship between the surface resistance and remotely sensed stress index
}

Abdelhakim Amazirh ${ }^{1}$, Salah Er-Raki ${ }^{*}$, Abdelghani Chehbouni ${ }^{2}$, Vincent Rivalland ${ }^{2}$, Alhousseine Diarra ${ }^{3}$, Said Khabba ${ }^{3}$, Jamal Ezzahar ${ }^{4}$, Olivier Merlin ${ }^{2,3}$

${ }^{1}$ LP2M2E, Département de Physique Appliquée, Faculté des Sciences et Techniques, Université Cadi Ayyad, Marrakech, Morocco ${ }^{2}$ CESBIO, Université de Toulouse, CNES/CNRS/IRD/UPS, Toulouse, France.

${ }^{3}$ LMME, Département de Physique, Faculté des Sciences Semlalia, Université Cadi Ayyad, Marrakech, Morocco ${ }^{4}$ MTI, ENSA, Ecole Nationale des Sciences Appliquées, Université Cadi Ayyad, Safi, Morocco

\begin{abstract}
Evapotranspiration (ET) plays an essential role for detecting plant water status, estimating crop water needs and optimising irrigation management. Accurate estimates of ET at field scale are therefore critical. The present paper investigates a remote sensing and modelling coupled approach for monitoring actual ET of irrigated wheat crops in the semi-arid region of Tensift $\mathrm{Al}$ Haouz (Morocco). The ET modelling is based on a modified Penman-Monteith equation obtained by introducing a simple empirical relationship between surface resistance $\left(r_{c}\right)$ and a stress index (SI). SI is estimated from Landsat-derived land surface temperature (LST) combined with the LST endmembers (in wet and dry conditions) simulated by a surface energy balance model driven by meteorological forcing and Landsat-derived fractional vegetation cover. The proposed model is first calibrated using eddy covariance measurements of ET during one growing season (2015-2016) over an experimental flood-irrigated wheat field located within the irrigated perimeter named R3. It is then validated during the same growing season over another dripirrigated wheat field located in the same perimeter. Next, the proposed ET model is implemented over a $10 \times 10 \mathrm{~km}^{2}$ area in R3 using a time series of Landsat-7/8 reflectance and LST data. The comparison between modelled and measured ET fluxes indicates that the model works well. The Root Mean Square Error (RMSE) values over drip and flood sites were 13 and $12 \mathrm{~W} \mathrm{~m}^{-2}$, respectively. The proposed approach has a great potential for detecting crop water stress and estimating crop water requirements over large areas along the agricultural season.
\end{abstract}

Keywords: Bulk surface resistance; Evapotranspiration; Crop water stress; Landsat; PenmanMonteith; Surface temperature. 


\begin{tabular}{|c|c|}
\hline Symbols & signification and unit \\
\hline ET & Evapotranspiration, mm \\
\hline rc & Surface resistance, $\mathrm{s} \mathrm{m}^{-1}$ \\
\hline $\mathbf{r}^{*}$ & Critical bulk resistance, $\mathrm{s} \mathrm{m}^{-1}$ \\
\hline $\mathbf{R}_{\mathbf{n}}$ & Net radiation, $\mathrm{W} \mathrm{m}^{-2}$ \\
\hline G & Soil heat flux, $\mathrm{W} \mathrm{m}^{-2}$ \\
\hline $\mathrm{H}_{\mathrm{EC}}$ & Sensible heat flux (eddy covariance), $\mathrm{W} \mathrm{m}^{-2}$ \\
\hline LEEC & Latent heat flux (eddy covariance), $\mathrm{W} \mathrm{m}^{-2}$ \\
\hline $\mathbf{u}_{\mathbf{a}}$ & Wind speed, $\mathrm{m} \mathrm{s}^{-1}$ \\
\hline $\mathbf{R}_{\mathbf{g}}$ & Solar radiation, $\mathrm{W} \mathrm{m}^{-2}$ \\
\hline $\mathbf{r h}_{\mathbf{a}}$ & Relative humidity, \% \\
\hline $\mathbf{T}_{\mathbf{a}}$ & Air temperature, ${ }^{\circ} \mathrm{C}$ \\
\hline $\mathbf{R}^{2}$ & Determination coefficient \\
\hline$\rho_{R}$ & Red spectral reflectance, $\%$ \\
\hline$\rho_{P I R}$ & Near infrared spectral reflectance, $\%$ \\
\hline$\varepsilon$ & Surface emissivity \\
\hline $\mathbf{k}$ & Attenuation coefficient \\
\hline$\Delta$ & Slope of the saturation vapour pressure curve at air temperature, $\mathrm{kPa}^{\circ} \mathrm{C}^{-1}$ \\
\hline$\gamma$ & Psychrometric constant, $\mathrm{kPa}^{\circ} \mathrm{C}^{-1}$ \\
\hline$\rho$ & Mean air density at constant pressure, $\mathrm{kg} \mathrm{m}^{-3}$ \\
\hline $\mathbf{c}_{\mathrm{p}}$ & Stands for the specific heat of air, $\mathrm{MJ} \mathrm{kg}^{-1}{ }^{\circ} \mathrm{C}^{-1}$ \\
\hline D & Vapour pressure deficit, $\mathrm{kPa}$ \\
\hline $\mathbf{e}_{\mathbf{a}}$ & Actual vapour pressure, $\mathrm{kPa}$ \\
\hline $\mathbf{e}_{\mathrm{s}}$ & Saturation vapour pressure, $\mathrm{kPa}$ \\
\hline rah, & Aerodynamic resistance, $\mathrm{s} \mathrm{m}^{-1}$ \\
\hline $\mathrm{Zr}$ & Reference height, $\mathrm{m}$ \\
\hline kar & Von Karman constant equal to 0.44 \\
\hline $\mathbf{h}_{\mathbf{c}}$ & Canopy height, $\mathrm{m}$ \\
\hline d & Displacement height, $\mathrm{m}$ \\
\hline $\mathbf{Z m}$ & Height of the dynamic soil roughness, $m$ \\
\hline$\psi_{\mathrm{m}}$ & Atmospheric stability function \\
\hline$\psi_{\mathrm{h}}$ & Sensitive heat stability function \\
\hline$\alpha$ & Surface albedo \\
\hline $\mathbf{R}_{\text {atm }}$ & Atmospheric longwave radiation, $\mathrm{W} \mathrm{m}^{-2}$ \\
\hline$\sigma$ & Stephan-Boltzmann constant equal to $5.67 \times 10^{-8}, \mathrm{~W} \mathrm{~m}^{-2} \mathrm{~K}^{-4}$ \\
\hline$\varepsilon_{\mathbf{a}}$ & Atmospheric emissivity \\
\hline$\Gamma$ & Fractional empirical coefficient set to 0.4 \\
\hline Fc & Fraction vegetation cover \\
\hline$a$ & Empirical coefficient equal to 0.17 \\
\hline b & Empirical coefficients equal to 0.8 \\
\hline$c$ & Empirical coefficients equal to 0.8 \\
\hline F (LST) & Cost function \\
\hline$d$ & Calibration parameters equal to $3000, \mathrm{~s} \mathrm{~m}^{-1}$ \\
\hline
\end{tabular}




\begin{tabular}{|c|c|}
\hline $\boldsymbol{e}$ & Calibration parameters equal to $-1130, \mathrm{~s} \mathrm{~m}^{-1}$ \\
\hline \multicolumn{2}{|c|}{ Abbreviation } \\
\hline LST & Land Surface Temperature, ${ }^{\circ} \mathrm{C}$ \\
\hline SI & Stress Index \\
\hline IPCC & International Panel on Climate change \\
\hline NDVI & Normalized Difference Vegetation Index \\
\hline LAI & Leaf Area Index \\
\hline SiSPAT & Simple Soil Plant Atmosphere \\
\hline ISBA & Interaction Soil-Biosphere-Atmosphere \\
\hline SVAT & Soil Vegetation Atmosphere Transfer \\
\hline ICARE & Interactive Canopy Radiation Exchange \\
\hline CERES & Crop Environment REsource Synthesis \\
\hline STICS & Simulateur multidisciplinaire pour les Cultures Standard \\
\hline Aquacrop & Crop-water productivity model \\
\hline SEBS & Surface energy balance model \\
\hline FAO-56 & Food and Agriculture Organization. No 56 \\
\hline PM & Penman-Monteith \\
\hline SEBI & Surface Energy Balance Index \\
\hline WDI & Water Deficit Index \\
\hline TVI & Temperature Vegetation Index \\
\hline TVDI & Temperature Vegetation Dryness Index \\
\hline VTCI & Vegetation Temperature Condition Index \\
\hline ETo & Evaporative demand, $\mathrm{mm}$ \\
\hline KH21 & Krypton hygrometer \\
\hline HPF01 & Soil heat flux plates \\
\hline CSAT3 & 3D sonic anemometer \\
\hline EC & Eddy covariance \\
\hline L7 & Landsat 7 \\
\hline L8 & Landsat 8 \\
\hline NASA & National Aeronautics and Space Administration \\
\hline USGS & United States Geological Survey \\
\hline MODTRAN & MODerate resolution atmospheric TRANsmission \\
\hline RMSE & Root Mean Square Error \\
\hline IPI & Irrigated Priority Index \\
\hline SLC & Scan line corrector \\
\hline H2020 & Horizon 2020 \\
\hline RISE & Research and Innovation Staff Exchange \\
\hline REC & $\begin{array}{l}\text { Root zone soil moisture Estimates at the daily and agricultural parcel scales for } \\
\text { Crop irrigation management - a multi-sensor remote sensing approach }\end{array}$ \\
\hline AMETHYST & $\begin{array}{l}\text { Assessment of changes in MEdiTerranean HYdro-resources in the South: river } \\
\text { basin Trajectories }\end{array}$ \\
\hline
\end{tabular}

\section{INTRODUCTION}


In arid and semi-arid regions, water scarcity is one of the main factors limiting agricultural development. Water scarcity is likely to be exacerbated in the near future under the combined effect of the alteration of the hydrological cycle, climate change and increasing water demand for agriculture, urban and industry (IPCC, 2009).

In Morocco, irrigation is the biggest consumer sector of water, in average, it has been estimated that about $85 \%$ of mobilised water resources is used by agriculture with an efficiency lower than $50 \%$ (Plan bleu, 2009). The Tensift Al Haouz region, which is considered as a typical watershed of the Southern Mediterranean, is characterised by a semi-arid climate. Under these conditions, irrigation is inevitable for crop growth, development and yield. For that a good irrigation management requires an accurate quantification of crop water requirements which is assumed equivalent to evapotranspiration (ET) (Allen et al., 2011).

During the last decades, several techniques have been proposed to estimate ET from local to global spatial scales. At the local scale, ET can be measured by using the sap flow sensors (Smith and Allen, 1996) that can provide the individual plant transpiration rate when the tree capacitance is neglected. Based on three different tree crop species, Motisi et al. (2012) verified that transpirational flow at orchard level is regulated by tree conductance, whereas capacitance effects are related to tree size or to environmental demand. ET can be also estimate at local scale by lysimetry (Edwards, 1986; Daamen et al., 1993). Passing from local to integrated spatial scales, the eddy covariance technique (Bedouchi et al., 1988; Allen et al., 2011) is suitable for measuring ET at the field scale over an homogeneous fields (1 ha and above). The eddy covariance and sap flow techniques can be jointly use to partition the ET in plant transpiration and soil evaporation (Cammalleri et al., 2013; Er-Raki et al., 2010). Another technique, is the scintillometry that can provide the sensible and latent heat flux over a transect ranging from $250 \mathrm{~m}$ to $10 \mathrm{~km}$ even for heterogeneous fields (Kohsiek et al., 2002; Ezzahar and Chehbouni, 2009). At global scale, remote sensing data in the optical/thermal bands provide several ET-related variables such as the Normalized Difference Vegetation Index (NDVI), surface albedo, surface emissivity, LAI (Leaf Area Index) and Land Surface Temperature (LST) (Granger, 2000; Clarson and Buffum, 1989). Several Authors have proposed the use of these methodologies (Hatefield, 1983; Moran and Jackson, 1991; Kustas, 1996; Kalma et al., 2008; Li et al., 2009; Allen et al., 2011; Er-Raki et al., 2013). All these techniques provide ET estimates at a specific temporal and spatial scales and rely on particular assumptions. Interpolation or extrapolation is thus often necessary to infer ET rates 
outside application scales, which can be a source of additional uncertainty. Moreover, most in situ techniques are expensive, time consuming and need a well-trained staff to operate and maintain it.

As an alternative to observational methods of ET, numerous modelling methods have been proposed such as Simple Soil Plant Atmosphere (SiSPAT) (Braud et al., 1995), Interaction SoilBiosphere-Atmosphere (ISBA) (Noilhan and Mahfouf, 1996) and simple SVAT (Soil Vegetation Atmosphere Transfer) (Boulet et al., 2000), Interactive Canopy Radiation Exchange (ICARE) (Gentine et al., 2007). Others models like Crop Environment REsource Synthesis (CERES) (Ritchie, 1986), Simulateur multidisciplinaire pour les Cultures Standard (STICS) (Brisson et al., 1998) and the crop-water productivity model (Aquacrop) (Raes et al., 2009) have combined the water balance with the crop growth, development and yield components. These modelling methods, whether complex or simple, are generally not easy to implement in an operational context as they require several parameters (e.g. soil and vegetation hydrodynamic properties) and forcing variables (e.g. climate and irrigation) that are often unavailable at the desired space and time scale. As a matter of fact, simpler models based on a few input data have been developed (Merlin, 2013; Merlin et al., 2014). Among them, the surface energy balance model (SEBS) estimates the turbulent fluxes and surface evaporative fraction $(\mathrm{Su}, 2002)$ by using remote sensing data (albedo, NDVI, emissivity and LST) in conjunction with meteorological forcing (solar radiation, air temperature, wind speed, air humidity) and surface parameters (e.g. roughness and stability correction functions for momentum and sensible heat transfer). In contrast, the FAO-56 model requires limited input parameters and it has been extensively and successful used for estimating ET over several agricultural areas such as : wheat (Er-Raki et al., 2007, 2010; Jin et al., 2017; Drerup et al 2017), olive (Er-Raki et al., 2008; Er-Raki et al., 2010; Rallo et al., 2014), citrus (Er-Raki et al., 2009; Rallo et al., 2017), table grapes (Er-Raki et al., 2013), sugar beet (Diarra et al., 2017; Anderson et al. 2017) and for different climate (Debnath et al., 2015; Ayyoub et al., 2017). It is based on the Penman-Monteith (PM) equation that has been formulated to include all the parameters that govern the energy exchange between vegetation and atmosphere. In the PM formulation, the extraction of water vapour from the surface is controlled by the surface resistance $\left(r_{c}\right)$. However, the PM approach has been limited by the difficulties to estimate $r_{c}$ as it depends on several factors related to pedological, biophysical and physiological processes, which are also related to agricultural practices (Katerji et al., 1991; Testi et al., 2004). 
To overcome these difficulties, many authors have used the concept of "critical bulk resistance, $r^{*}$, where $r^{*}$ is $r_{c}$ when evapotranspiration is not affected by wind speed (Katerji and Perrier, 1983). The critical bulk resistance depends only on other local meteorological variables. Rana et al. (2005) and Ayyoub et al. (2017) showed that $r_{c}$ is linearly related to $r^{*}$, allowing the ET estimates even in water shortage conditions. It has been demonstrated that the use of the critical resistance approach to estimate canopy resistance that varies with local meteorology provides more accurate ET estimates than assuming a constant value of resistance for a given canopy (Katerji and Rana, 2006). Alves and Pereira (2000) further investigated the surface resistance in the PM equation and suggested that the surface resistance integrates the combined effects of stomatal, soil surface and canopy resistances. They also showed that the surface resistance depends on meteorological variables as in Jarvis (1976). This approach has then been confirmed by Katerji and Perrier (1983) who showed that decoupling the surface resistance (function of critical resistance), from atmospheric resistance effects improves ET estimates, and this is consistent with the study of Alves and Pereira (2000). All those methods estimate the surface resistance and ET at local scale but little attention has been paid on determining $r_{c}$ at large scale from remote sensing data. Since the crop water stress is related to $r_{c}$ through stomatal closure, one can estimate $r_{c}$ from remotely sensed LST which can provide a good proxy for water stress level.

Several stress indexes have been developed such as the Surface Energy Balance Index (SEBI, Mensenti et al., 1993), Water Deficit Index (WDI, Moran et al., 1944; Moran, 2004), Temperature Vegetation Index (TVI, Prihodko et al., 1997), Temperature Vegetation Dryness Index (TVDI, Sandholt et al., 2002) and Vegetation Temperature Condition Index (VTCI, Wang et al., 2004; Wan et al., 2004). VTCI is defined as a ratio of the dry to actual LST difference to the dry to wet LST temperature difference, with wet/dry LST being estimated as the minimum/maximum LST that the surface can reach for a given meteorological forcing. Among existing thermal-based stress indexes, VTCI has two main advantages: 1) it is rather physically-based due to possibility of simulating wet/dry LST values using a surface energy balance model (Wang et al., 2001) and 2) it can be applied to mixed pixels including soil and vegetation components. In this context, the objective of this study is to model ET based on the modified PM equation by introducing a simple established relationship between $r_{c}$ and a thermal-based proxy of vegetation water stress, since it was considered as the most relevant parameter for drought monitoring (Jakson et al., 1981; Wan et al., 2004). The surface water stress index (SI) will be derived from the VTCI estimated either from 
in situ or Landsat thermal/reflectance remote sensing data. After, the approach is calibrated and tested in terms of ET estimates over both flood and drip irrigated sites.

\section{MATERIALS AND METHODS}

\subsection{Site description}

A field experiment was conducted over wheat crops in the Tensift region in central Morocco. This area has a semi-arid Mediterranean climate, characterised by low and irregular rainfall with an annual average of about $240 \mathrm{~mm}$, against an evaporative demand $\left(\mathrm{ET}_{0}\right)$ of $1600 \mathrm{~mm}$ year ${ }^{-1}$. The study site is located in the irrigated zone R3 in the Haouz plain, approximately $40 \mathrm{~km}$ southwest of Marrakech city (see Figure 1). The experiment was carried out during the 2015-2016 growing season in two irrigated wheat fields: a 2 ha drip-irrigated field and a 4 ha flood-irrigated field. The surrounding of two fields is also cultivated with wheat and beans for the drip-irrigated one. The soil of both sites has low sand and high clay contents (47\% clay, $35 \%$ silt, and $18 \%$ sand). The sowing dates were the $13^{\text {th }}$ and $22^{\text {th }}$ December 2015 for the drip and flood irrigated sites, respectively.

\subsection{Ground data description}

During the investigated agricultural season, both wheat sites were equipped with all sensors necessary for measuring different water and heat fluxes exchanged between soil, vegetation and atmosphere. The net radiation $\left(\mathrm{R}_{\mathrm{n}}\right)$ was measured by the net radiometer (Kipp and Zonen CNR4, Campbell Sci). Soil heat flux (G) was controlled at a $5 \mathrm{~cm}$ depth using soil heat flux plates (HPF01, Campbell Sci). Radiometric brightness temperature was measured using an Infra-Red Thermometer (IRTS-P's, Apogee) and then converted to LST using surface emissivity. An eddy covariance system, consisting of a 3D sonic anemometer (CSAT3, Campbell Scientific Ltd.) and a Krypton hygrometer (KH21, Campbell Scientific Ltd.), was installed to provide continuous measurements of vertical sensible heat $\left(\mathrm{H}_{\mathrm{EC}}\right)$ and latent heat (LEEC) fluxes. Half-hourly measurements of classical meteorological data were collected over a grass cover using an automatic meteorological weather station: wind speed $\left(\mathrm{u}_{\mathrm{a}}\right)$, incoming solar radiation $\left(\mathrm{R}_{\mathrm{g}}\right)$, air relative humidity $\left(\mathrm{rh}_{\mathrm{a}}\right)$ and air temperature $\left(\mathrm{T}_{\mathrm{a}}\right)$ at a reference height $(2 \mathrm{~m})$.

Before using the data of latent heat flux (equivalent to ET) measured by the eddy covariance system, it is important to check the reliability and the quality of these measurements. This is 
undertaken through the analysis of the energy balance closure. By ignoring the term of canopy heat storage and the radiative energy used by vegetation photosynthesis (Testi et al., 2004), the energy balance closure is defined as:

$$
R_{n}-G=H_{E C}+L E_{E C}
$$

To check the budget closure during the study period, we compared the available energy at the surface $\left(R_{n}-G\right)$ with the sum of turbulent fluxes $\left(H_{E C}+L E_{E C}\right)$ at half-hourly scale. The quality of the correlation between $\left(\mathrm{R}_{\mathrm{n}}-\mathrm{G}\right)$ and $\left(\mathrm{H}_{\mathrm{EC}}+\mathrm{LEEC}_{\mathrm{EC}}\right)$ was evaluated by the regression line and the determination coefficient $\mathrm{R}^{2}$. Figure 2 shows the energy budget closure for sub-hourly data during 2015-2016 growing season for both study sites separately.

Results show that the closure of the energy balance is relatively well verified by comparison with other studies (Testi et al., 2004; Ezzahar et al., 2009). The regression lines are close to the 1:1 line and $\mathrm{R}^{2}$ values are generally close to $1(0.91$ and 0.88 for the flood and drip irrigated fields, respectively). However, the slope of the regression forced through the origin was about 1.3 for both sites, indicating some underestimation of turbulent fluxes $\left(\mathrm{H}_{\mathrm{EC}}+\mathrm{LE}_{\mathrm{EC}}\right)$ by about $30 \%$ of the available energy $\left(R_{n}-G\right)$. This due to the attenuation of turbulence at low or high frequency signals (Ezzahar et al., 2009). Also, the difference between the sensors source area has a very important impact on the energy balance closure. In fact, the surface area of the sensors measuring the available energy (net radiation and soil heat flux) is very small compared to that of EC system, which can quickly change depending on wind speed and direction and surface conditions. Moreover, the energy absorbed by the plant has not been considered in the energy balance. In this context, Scott et al. (2003) evaluated the storage in the biomass to about 5-10 \% of the available energy, which could partially explain the overestimation of available energy at the surface.

\subsection{Remote sensing data}

Landsat 7 (L7) and Landsat 8 (L8) satellites were launched by NASA on April 1999 and February 2013, respectively. The combined use of both satellites potentially provides repetitive acquisitions every 8 days of high (30 -100 m) resolution multispectral data of the Earth's surface on a global basis. The data (available for download from the USGS website, https://earthexplorer.usgs.gov/) are resampled to $30 \mathrm{~m}$ resolution. A total of 14 images (6 and 8 images for L7 and L8, respectively) were used in this study. They were acquired from January 2016 until the end of the agricultural season (end of May). 
Herein, Landsat data were used to estimate the NDVI, surface emissivity and LST over the R3 area overlaying both study sites. NDVI is calculated using the spectral reflectance measurements acquired in the visible $\rho_{R}$ (red) and near-infrared regions $\rho_{P I R}$ :

$$
\mathrm{NDVI}=\frac{\rho_{\mathrm{PIR}}-\rho_{\mathrm{R}}}{\rho_{\mathrm{PIR}}+\rho_{\mathrm{R}}} .
$$

The surface emissivity was estimated from an empirical relationship with NDVI and soil/vegetation emissivity components:

$$
\varepsilon=\varepsilon_{\mathrm{v}}-\left(\varepsilon_{\mathrm{v}}-\varepsilon_{\mathrm{s}}\right)\left(\frac{\mathrm{NDVI}-\mathrm{NDVI}_{\mathrm{v}}}{\mathrm{NDVI}_{\mathrm{s}}-\mathrm{NDVI}_{\mathrm{V}}}\right)^{\mathrm{k}}
$$

where $\varepsilon_{v}$ is the vegetation emissivity (set to 0.99 ), $\varepsilon_{s}$ is the soil emissivity (set to 0.96 ), $\mathrm{NDVI}_{\mathrm{v}}$ is NDVI for full vegetation (set to 0.99), $\mathrm{NDVI}_{\mathrm{s}}$ is the NDVI for bare soil (set to 0.15). $\mathrm{k}$ is an attenuation coefficient relevant to the relation between LAI-NDVI and NDVI-emissivity ranging from 2 to 3. In Olioso et al. (2013) the value of $\mathrm{k}$ is derived from the shape of the NDVIemissivity relationship for a range of soil moisture conditions and vegetation canopy emissivities. In our case, it was adjusted to 2 based on the NDVI-LAI relationship established in the same region by Er-Raki et al. (2007). Note that this value was used in Tardy et al. (2016) over the same (semi-arid) region.

LST was derived from the thermal infrared bands passing by different correction steps defined in Tardy et al., (2016). Those steps allowed to convert the Landsat digital number to the physical LST by inverting the Plank's low. An atmospheric correction of the thermal infrared bands data was firstly carried out using the MODTRAN atmospheric radiative transfer model software. For doing that, knowledge of the humidity and air temperature profile was needed. As second step, the at-sensor radiance was converted into surface radiance using the estimated surface emissivity. Then the LST was obtained by inverting the Plank's law. In order to evaluate the spaceborne LST, a comparison between the Landsat-derived against in situ LST measurements is presented in Figure 3.

According to this figure, a relatively good match between satellite and ground LST data is obtained for the flood irrigated wheat parcel with a determination coefficient $\left(\mathrm{R}^{2}\right)$ of 0.92 and a RMSE equal to $0.91{ }^{\circ} \mathrm{C}$, whereas an $\mathrm{R}^{2}$ of 0.80 and an RMSE equal to $2.36{ }^{\circ} \mathrm{C}$ are found for the drip-irrigated field. The systematic over-estimation observed in the drip site could be attributable to the spatial extent of in situ and spaceborne observations. In fact, the drip-irrigated site is small (in comparison with the flood one), and does not fully cover the Landsat thermal pixel size (100 m resolution). Moreover, some differences between in situ and Landsat data could be explained by 
the limited spatial representativeness of 2-m high in situ thermal data. In addition, the better results in flood irrigated field than in drip irrigated field is due to: 1) The irrigation system: as it is known, flood irrigation implies a homogeneous fraction of wetted areas, where all the pixels have the same percentage of irrigation water, which means an uniform LST within the site. In contrast, just a part of the soil surface is wetted in the drip irrigated site, which may lead to some heterogeneity in observed LST from one pixel to another. 2) The flood irrigated site is bigger (4 hectares) than the drip one (approximately 2 hectares with a surface area of 4 ha (35 Landsat pixels) and 2 ha (10 Landsat pixels), respectively. Note that several 60/100 m Landsat LST pixels were partly covering the surrounding fields, causing representativeness issues especially for the smaller (drip) field. In addition 3) for the flood site, the surrounding fields are similar with the same irrigation system and crop (wheat). Contrariwise, the drip one, was surrounded by fields with different crops (beans).

The observed overestimation of LST by Landsat could also be due to an overestimation of the surface emissivity. As soil emissivity is difficult to estimate without specific measurements (unavailable in this experiment), it was fixed arbitrarily to 0.95 . Moreover, we would like to underline that the field measurements of LST are representative of a small square of the surface only, which is much smaller than a Landsat pixel. Last each crop field can include a mixture of wet and dry Landsat pixels, although an average of all LST values was computed at the field scale.

\subsection{EVAPOTRANSPIRATION MONITORING APPROACH}

\subsubsection{Evapotranspiration modelling}

The latent heat flux (LE $\left(\mathrm{W} \mathrm{m}^{-2}\right)$ ) of wheat was modelled by using the following PM equation:

$$
\mathbf{L E}=\frac{\Delta\left(\mathrm{R}_{\mathrm{n}}-\mathrm{G}\right)+\rho \mathrm{c}_{\mathrm{p}_{\mathrm{r}, \mathrm{h}}} \frac{\mathrm{D}}{\mathrm{r}_{\mathrm{a}}}}{\Delta+\gamma\left(1+\frac{\mathrm{r}_{\mathrm{C}}}{\mathrm{r}_{\mathrm{a}, \mathrm{h}}}\right)}
$$

where $\Delta$ stands for the slope of the saturation vapour pressure curve at air temperature $\left(\mathrm{kPa}^{\circ} \mathrm{C}^{-1}\right)$. The psychrometric constant $\left(\mathrm{kPa}^{\circ} \mathrm{C}^{-1}\right)$ and the mean air density at constant pressure $\left(\mathrm{kg} \mathrm{m}^{-3}\right)$ are presented by $\gamma$ and $\rho$ respectively while $c_{p}$ stands for the specific heat of air $\left(\mathrm{MJ} \mathrm{kg}^{-1}{ }^{\circ} \mathrm{C}^{-1}\right)$. The vapour pressure deficit; $\mathrm{D}(\mathrm{kPa})$ is obtained by calculating the difference between the air vapour pressure; $\mathrm{e}_{\mathrm{a}}(\mathrm{kPa})$ and the saturated water vapour pressure; $\mathrm{e}_{\mathrm{s}}(\mathrm{kPa})$ where the latter is calculated as addressed in equation 5 . 


$$
e_{s}=0.611 \times e^{\left(\frac{17.27 \times T_{a}}{T_{a}+273.3}\right)}
$$

In Equation (4), all parameters are deduced from the meteorological variables measured by the automatic meteorological station. However, the use of this model requires determining the aerodynamic resistance $\left(r_{a h}, \mathrm{~s} \mathrm{~m}^{-1}\right)$ and bulk canopy resistance $\left(r_{c}, s^{-1}\right) . r_{a h}$ is calculated at a reference height $z_{r}$ in the boundary layer above the canopy by:

$$
\mathrm{r}_{\mathrm{ah}}=\frac{\left(\log \left[\left(\mathrm{z}_{\mathrm{r}}-\mathrm{d}\right) / \mathrm{zm}\right]-\psi_{\mathrm{m}}\right) \times\left(\log \left[\left(\mathrm{h}_{\mathrm{c}}-\mathrm{d}\right) / \mathrm{zm}\right]-\psi_{\mathrm{h}}\right)}{\mathrm{kar}^{2} \times \mathrm{u}_{\mathrm{a}}}
$$

where kar is the Von Karman constant equal to $0.44, \mathrm{~h}_{\mathrm{c}}$ the canopy height, the displacement height (to adjust the effects of vegetation height on wind displacement) and the height of the dynamic soil roughness are presented as , $\mathrm{d}=2 / 3 \mathrm{~h}_{\mathrm{c}}$ and $\mathrm{z}_{\mathrm{m}}=\mathrm{h}_{\mathrm{c}} / 8$ respectively. The $\psi_{\mathrm{m}}$ and $\psi_{\mathrm{h}}$ presents the atmospheric stability function and the sensitive heat stability function, respectively.

For irrigated crops, the canopy resistance $r_{c}$ is not assumed to be constant. It changes according to available energy, vapour pressure deficit, and other environmental factors. In this study, we propose to use a simple empirical relationship between $r_{c}$ and a vegetation water stress index (SI) which is calculated as:

$$
\mathrm{SI}=1-\mathrm{VTCI}
$$

where VTCI is calculated as follow:

$$
\mathrm{VTCI}=\frac{\mathrm{LST}_{\mathrm{dry}}-\mathrm{LST}}{\mathrm{LST}_{\mathrm{dry}}-\mathrm{LST}_{\mathrm{wet}}}
$$

where $\mathrm{LST}_{\text {wet }}$ and $\mathrm{LST}_{\text {dry }}$ are the LST simulated by an energy balance model in fully wet and dry surface conditions, respectively (Stefan et al., 2015; Merlin et al., 2016). We therefore distinguish between stressed and unstressed conditions via the VTCI. Especially, VTCI equals $1(\mathrm{SI}=0)$ for $\mathrm{LST}=\mathrm{LST}_{\text {wet }}$ (energy-limited evaporation), which means that vegetation is unstressed and the

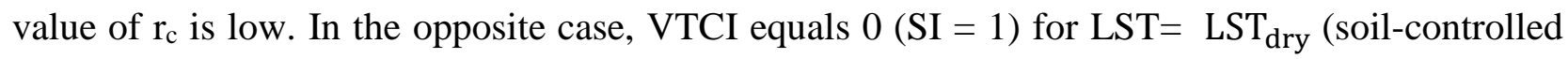
evaporation), which means that vegetation is undergoing water stress and the value of $r_{c}$ is large.

\subsubsection{Energy balance Model}

The two extreme temperatures ( $\mathrm{LST}_{\text {wet }}$ and $\mathrm{LST}_{\mathrm{dry}}$ ) of Equation (8) are simulated by running an energy balance model forced by $\mathrm{r}_{\mathrm{c}} \approx 0 \mathrm{~s} \mathrm{~m}^{-1}$ and $\mathrm{r}_{\mathrm{c}} \approx \infty$, respectively. The surface net radiation is expressed as:

$$
R_{n}=(1-\alpha) R_{g}+\varepsilon\left(R_{a t m}-\sigma L S T^{4}\right)
$$


272 with $\alpha(-)$ being the surface albedo (set to 0.20), $\mathrm{R}_{\mathrm{atm}}$ stands for the atmospheric longwave 273 radiation $\left(\mathrm{W} \mathrm{m}^{-2}\right)$ and $\sigma=5.67 \times 10^{-8}$ the Stephan-Boltzmann constant $\left(\mathrm{W} \mathrm{m}^{-2} \mathrm{~K}^{-4}\right)$. The 274 downward atmospheric radiation at surface level is expressed as:

$$
\mathrm{R}_{\mathrm{atm}}=\varepsilon_{\mathrm{a}} \times \sigma \mathrm{T}_{\mathrm{a}}^{4}
$$

where $\varepsilon_{\mathrm{a}}$ is the atmospheric emissivity estimated as in Brutsaert (1975):

$$
\varepsilon_{\mathrm{a}}=1.24 \times\left(\frac{\mathrm{e}_{\mathrm{a}}}{\mathrm{T}_{\mathrm{a}}}\right)^{\frac{1}{7}}
$$

278 with

$$
\mathrm{e}_{\mathrm{a}}=\mathrm{e}_{\mathrm{s}}\left(\mathrm{T}_{\mathrm{a}}\right) \times \frac{\mathrm{rh}_{\mathrm{a}}}{100}
$$

279 The ground flux $G$ is estimated as a fraction of net radiation at the soil surface $R_{n, s}$ :

$$
\mathrm{G}=\Gamma \cdot \mathrm{R}_{\mathrm{n}, \mathrm{s}}
$$

281 with $\Gamma$ being a fractional empirical coefficient set to 0.4 , and $\mathrm{R}_{\mathrm{n}, \mathrm{s}}$ is given by:

$$
\mathrm{R}_{\mathrm{n}, \mathrm{s}}=\mathrm{R}_{\mathrm{n}} \times(1-\mathrm{Fc})
$$

with Fc being the fraction vegetation cover calculated as:

$$
\mathrm{Fc}=\left(\frac{\mathrm{NDVI}-\mathrm{NDVIs}}{\mathrm{NDVI}_{\mathrm{V}}-\mathrm{NDVI}_{\mathrm{S}}}\right)
$$

285 The sensible heat flux is given by:

$$
H=\rho c_{p} \beta \frac{L S T-T_{a}}{r_{a, h}}
$$

where $\beta$ is the " $\beta$ function" calculated as follows as a function of LAI:

$$
\beta=1-\frac{a}{L A I * b * \sqrt{2 \pi}} e^{-\frac{(\ln (L A I)-c)^{2}}{2 * b^{2}}}
$$

with $a, b$ and $c$ are empirical coefficients equal to 0.17 for $a$ and 0.8 for $b$ and $c$ (Boulet et al., 290 2012). These values are calibrated for the wheat in the same study site.

291 The latent heat flux is estimated using the following equation:

$$
\mathrm{LE}=\frac{\rho \mathrm{c}_{\mathrm{p}}}{\gamma} \frac{\mathrm{e}_{\mathrm{s}}-\mathrm{e}_{\mathrm{a}}}{\mathrm{r}_{\mathrm{a}, \mathrm{h}}+\mathrm{r}_{\mathrm{c}}}
$$

293 Finally, for running the energy balance model, it was set LST = Ta and search for the value of 294 295 LST that minimises the following cost function F (LST):

$$
\mathbf{F}(\mathbf{L S T})=(\mathbf{R n}-\mathbf{G}-\mathbf{H}-\mathbf{L E})^{2}
$$


F (LST) is named "cost function" as it is the function to be minimised in order to find the LST value corresponding to the energy balance closure (e.g. Merlin et al., 2016).

\section{RESULTS AND DISCUSSIONS}

The PM equation is used in this study to estimate the surface ET of wheat over two different crop fields in terms of irrigation systems located in the R3 area. The proposed approach aims to modify the PM equation by expressing $r_{c}$, which is the main parameter controlling latent heat flux, as a function of a thermal-derived SI. The use of LST as an indicator of the surface resistance in order to estimate the ET, is assessed by using the in situ measurements collected in the flood-irrigated site. The "observed" $r_{c}$ is estimated by inverting Equation (3) using ET measured by eddy covariance system. Then, a validation exercise is carried out over the drip irrigated-site using in situ data. Finally, an evaluation of the method is undertaken using Landsat data over both sites.

\subsection{In situ evaluation of the proposed approach}

The time series of retrieved SI and $r_{c}$ over the flood site is shown in Figure 4. According to this figure, daily patterns of SI and $r_{c}$ are similar and respond perfectly to the water supply (rainfall or irrigation). On one hand, after water supply, the soil moisture in the root zone increases and the plant transpirates at potential rate with no limitation and the values of $r_{c}$ and SI tend to decrease. On another hand, the absence of irrigation and rainfall (dry condition, e.g. from the end of April) results in an increase in the root zone depletion and generates stress (SI increased). The increase in soil water depletion is due to the removal of water by ET that induces water stress conditions and then the stomatal closure which increases $r_{c}$. Consequently, it can be concluded that both the variables follow similar trends. This leads to look if there is any relationship between both terms. For this purpose, $r_{c}$ is plotted against SI (Figure 5) by using in situ measurements (flood site). When SI ranges from 0 to 0.4 which corresponds to unstressed vegetation with low LST values, $r_{c}$ values are scattered around a mean value of about $70 \mathrm{~s} \mathrm{~m}^{-1}$ which corresponds to the minimum bulk surface resistance $\left(r_{c m i n}\right)$.

The obtained value of $r_{c m i n}$ is in agreement with values obtained for wheat crop by Baldocchi (1994). When SI increases above a threshold value SI $=0.4, r_{c}$ increases linearly with SI. This confirms the results reported by Autovino et al. (2016) and Er-Raki et al. (2016) who found a 
similar shape for olive and orange orchards, respectively. The obtained relationship, which gives the best fit between both terms, is given by:

$$
\begin{array}{ll}
r_{c}=r_{\text {cmin }}=70 \text { s. } m^{-1} & \text { for } S I<0.4 \\
r_{c}=d * S I+e & \text { for } S I \geq 0.4
\end{array}
$$

where $d$ and $e$ are the calibration parameters, which are equal to $3000 \mathrm{~s} \mathrm{~m}^{-1}$ and $-1130 \mathrm{~s} \mathrm{~m}^{-1}$, respectively. Note that the values of $r_{c m i n}, d$ and $e$ are expected to depend on local meteorological data, crop and soil types.

The relationship of Equation (19) is validated by comparing the modelled and measured latent heat flux for the drip-irrigated wheat site at Landsat overpass time (Figure 6). According to this figure, an acceptable correlation is obtained between simulated and measured LE using the proposed approach $\left(\mathrm{R}^{2}=0.53\right)$. The scatter of modelled LE estimates is probably due to the uncertainties associated to the relatively small footprint of the in situ thermal radiometer. Looking at the dynamics of actual LE and $r_{c}$ values estimated by Equation (19) (not showed in the manuscript), the proposed methodology for bulk resistance estimation allows for capturing the variability of measured LE. The significant bias in simulated LE is probably due to the underestimation of in situ LST, involving an overestimation of simulated LE especially during the dry period (Ramelo et al 2014; Ruhoff at al., 2013). Those explanations were added to the revised version.

\subsection{Spatial analysis}

To overcome the spatial representativeness issue of in situ measurements and for further evaluating the proposed model, Landsat data are used as input of the modified PM model. ET estimates are spatialized within a $10 \times 10 \mathrm{~km}^{2}$ area centred over the R3 sector which is mainly covered by wheat crops. The R3 perimeter is occupied by different cultures (wheat, alfalfa, orange, and olive), so before spatializing the ET, a land use has been performed in order to distinguish between wheat and other crops. Figure 7 shows the spatial and temporal variations of Landsat-derived LST and Fc over wheat crops. As the entire growing season of wheat was divided into four growth stages namely: the initial, the development, the mid-season and the late season, we choose to present one image for each stage (Figure 7). This figure shows that during the initial stage (06/01/2016), most of the fields were under bare soil conditions characterised by low Fc and high LST values depending spatially on the water supply and atmospheric conditions. In the 
development stage (07/02/2016) an effective full cover is reached in some parcels while other ones are characterized by low Fc depending on the sowing date and the development of vegetation. This spatial variability of Fc has a direct effect on the variability of LST. When Fc reaches the maximum value at the mid-season (18/03/2016), spatial LST values are similar around $20{ }^{\circ} \mathrm{C}$ except for some pixels where the LST values are relatively higher (about $35{ }^{\circ} \mathrm{C}$ ), which correspond to the non-cultivated parcels. At the last stage (29/05/2016), from the beginning of maturity until harvest or full senescence, wheat fields are characterized by low Fc and high LST values.

Our approach involves the energy balance model in order to assess the variation of LST in space and time for two extreme dry and wet conditions which depend on climatological conditions. Figure 8 shows the dry and wet LST maps for the selected four dates. These maps show that, in the coldest days in winter $(06 / 01 / 2016)$, the $\operatorname{LST}_{\text {dry }}$ oscillated between 15 and $30{ }^{\circ} \mathrm{C}$ and the $\mathrm{LST}_{\text {wet }}$ ranged from 10 to $17^{\circ} \mathrm{C}$. In the other hand, for the hottest days in summer (29/05/2016), the $\operatorname{LST}_{\text {dry }}$ reached its maximum $\left(50{ }^{\circ} \mathrm{C}\right)$ as well as the $\mathrm{LST}_{\text {wet }}$ that reached $30^{\circ} \mathrm{C}$.

The use of LST time series extracted from Landsat satellite and the dry and wet LST values computed using the energy balance model appears to be a good way to monitor water stress index for irrigation scheduling. Figure 9 presents the spatial distribution of SI over R3 perimeter at the different growth stages. The maps of this figure show that Landsat-derived SI consistently ranges between 0 and 1 all along the agricultural season, regardless of the vegetation cover fraction and LST values (see Figure 7). In fact, the use of Fc and LST data as input variables of the energy balance model to estimates $\mathrm{LST}_{\mathrm{dry}}$ and $\mathrm{LST}_{\text {wet, }}$ allows taking into account all the growing stages of wheat crop. In particular, we can distinguish between the small vegetation (tillering stage) and the full developed one (mid-season stage). In this regard Barbosa da Silva and Rao (2005) estimated SI of cotton crop using LST, $r_{c}$ and $R_{n}$. However, they did not take into account the vegetation parameters and their variability during the agricultural season. These parameters affect the aerodynamic resistance and hence both the sensible and latent heat fluxes.

In Figure 9, the pixels having a SI value close to 1 (red colour) are characterised by a high vegetation stress due to the mismatch between water supply and water requirement (late irrigation). The values of SI ranging between 0.3 and 0.6 are characterised by the onset of vegetation stress. This is due to the difficulty of the irrigation distribution at the right moment. Indeed, the water transported by gravity across the R3 channels may arrive to the fields before or after the optimal date (Belaqziz et al., 2013; Belaqziz et al., 2014). Pixels with SI values around 0 
correspond to un-stressed, meaning recently irrigated wheat. Following the evolution of SI, it appears that this index shows spatial and quantitative information about the method of irrigation distribution, and could be used to optimise the irrigation scheduling. Those results are consistent with the work of Belaqziz et al. (2013), who used another index named "Irrigated Priority Index (IPI)" in the same study area to manage the irrigation distribution. The IPI equation is mainly based on both the water stress level and irrigation dates of wheat crop. The main drawback of IPI is that it needs the amount of water supply as input, which is not the case of SI developed. This new index based on LST only might then be combined with IPI in order to detect and retrieve irrigation amount, information that is very difficult to obtain over large areas.

Figure 10 shows the spatial distribution of ET and its temporal variation across the season. We can observe a high variability of ET, which depends on the spatial heterogeneity of Fc, LST and SI over R3.

The spatial representation allowed to distinguish between the fields corresponding to stressed wheat (blue colour) where LE is lower and the field corresponding to un-stressed fields (other colour) that have been relatively well irrigated during the wheat growing stages, for high ET values. The obtained spatial and temporal variations of ET are in accordance with the spatiotemporal variability of Fc, LST and SI (see Figures 7, 9). To observe this more easily, the frequency histograms for remote sensing data (Fc, LST), SI and ET on one date 18/03/2016 are plotted in Figure 11. The choice of this date relies on the fact that the end of March summarises the history of wheat crop growth and its development from sowing date (Karrou., 2003; Hadria., 2006). By analysing the different histograms, one can be concluded that the estimates LE are coherent with other surface properties (Fc, LST, and SI). Fc values in the higher range (larger than 0.8) have a high frequency/percentage. They correspond to the fields with low LST values (lower than $25^{\circ} \mathrm{C}$ ), which are associated to small values of surface aerodynamic resistance (large crop height) rather than to large water availability for wheat. On this date, our model computes a large amount of un-stressed areas with relatively small SI and large LE values. Those results seem to be representative of the real situation.

The land surface parameters (LST, Fc, and emissivity) are obtained from Landsat data. Therefore all cloudy data (images) are discarded. In addition, the Landsat-7 images include data gaps due to scan line corrector (SLC) failure on May 31 2013, which on some dates unfortunately covered the irrigated sites. The selected data are used for validating the predicted ET (Equation 4) against in situ ET for both flood and drip sites (Figure 12). As it can be observed in this figure, the proposed 
419 approach allows to predict correctly the temporal dynamics of ET with an acceptable accuracy and 420 a good correlation. The validations for the two sites resulted in $\mathrm{R}^{2}$ of $0.76,0.70$ and a RMSE of $42112,13 \mathrm{~W} \mathrm{~m}^{-2}$ for flood-irrigated site and drip-irrigated site, respectively.

422 A further validation of the proposed approach was performed by comparing the measured ET 423 with the ET simulated one under fully stressed $\left(\mathrm{SI}=1, \mathrm{r}_{\mathrm{c}}=1870 \mathrm{~s} \mathrm{~m}^{-1}\right)$ and un-stressed $\left(\mathrm{SI}=0, \mathrm{r}_{\mathrm{c}}\right.$ $424=70 \mathrm{~s} \mathrm{~m}^{-1}$ ) conditions. The obtained results are presented in the same Figure 12 under real 425 meteorological conditions. As expected, the model simulates very low values of ET for SI=1 426 whereas it simulates high values of ET for $\mathrm{SI}=0$. On some dates, the ET simulations with $\mathrm{SI}=0$ $427\left(r_{c}=70 \mathrm{~s} \mathrm{~m}^{-1}\right)$ coincides with the ET estimated from Landsat-derived SI, which means that the 428 fields were monitored in well-watered conditions (SI < 0.4). One key result is that the Landsat429 derived SI $\left(0<\mathrm{SI}<1,70<\mathrm{r}_{\mathrm{c}}<1870 \mathrm{~s} \mathrm{~m}^{-1}\right)$ provides much more accurate ET estimates over both 430 validation sites than when assuming fully stressed $\left(\mathrm{SI}=1, \mathrm{r}_{\mathrm{c}}=1870 \mathrm{~s} \mathrm{~m}^{-1}\right)$ or fully unstressed $431 \quad\left(\mathrm{SI}=0, \mathrm{r}_{\mathrm{c}}=70 \mathrm{~s} \mathrm{~m}^{-1}\right)$ condition in the PM equation.

\section{CONCLUSION}

433 434 435 436 437 438 439 440

The aim of this study was to use the PM equation to estimate the evapotranspiration (ET) over irrigated wheat crops of semi-arid areas. As the PM approach has been limited by the difficulties to estimate the bulk surface resistance $\left(r_{c}\right)$ since it depends on several factors related to crop characteristics and agricultural practices, we proposed in this study to link $r_{c}$ to the stress index (SI) derived from remotely sensed LST and to implement the developed relationship in the PM model. SI was estimated as the observed LST normalized by the LST simulated in fully wet and dry conditions using a surface energy balance model forced by meteorological forcing and vegetation fraction.

The approach was tested over a $10 \times 10 \mathrm{~km}^{2}$ irrigated perimeter R3. The calibration/validation strategy implements two instrumented wheat sites with flood and drip irrigation and Landsat shortwave and thermal imagery during one growing season (2015-2016). The $\mathrm{r}_{\mathrm{c}}$ retrieved from eddy covariance measurements over the flood-irrigated site (by inverting PM equation) was first correlated to SI. This relation was then tested over the drip-irrigated site using in situ measurements in order to simulate the surface ET. Next, this method was evaluated in terms of latent heat flux using Landsat temperature and reflectance data over both sites. The RMSE values 
448 over drip and flood sites are 13 and $12 \mathrm{~W} \mathrm{~m}^{-2}$, which correspond to the relative errors of 5 and $4494 \%$, respectively.

450 The proposed relationship between $r_{c}$ and SI employed in the PM model holds great potential for 451 estimating crop ET using remote sensing data. Moreover, the results reached in terms of 452 detecting crop water stress, can be helpful to distinguish between the irrigated and non-irrigated 453 areas, which could give a prevision of the wheat yield based on the IPI developed by Belaqziz et 454 al. (2013). Note however that the proposed methodology has been tested over two wheat parcels 455 only. Further calibration studies should be undertaken to investigate and understand the 456 variability of $r_{c}$ parameters over different crop types and surface conditions.

457

458 459 460 461 462 463 464 465 466 467 468 469 470 471 472 473 474 475

\section{ACKNOWLEDGEMENT}

This study was conducted within the International Joint Laboratory-TREMA (http://trema.ucam.ac.ma). This work was supported by the European Commission Horizon 2020 Programme for Research and Innovation (H2020) in the context of the Marie SklodowskaCurie Research and Innovation Staff Exchange (RISE) action (REC project, grant agreement no: 645642), SAGESSE (PPR program funded by the Moroccan Ministry of Higher Education), and ANR AMETHYST project (ANR-12-TMED-0006-01).

\section{REFERENCE}

Allen, R.G., Pereira, L.S., Howell, T.A., Jensend, M.E. (2011). Evapotranspiration information reporting: I. Factors governing measurement Accuracy. Agricultural Water Management. 98, 899-920.

Alves, I., Pereira, L.S. (2000). Modelling surface resistance from climatic variables? Agricultural Water Management. 42, 371-385.

Autovino, D., Minacapilli M., Provenzano G. (2016). Modelling bulk surface resistance by MODIS data and assessment of MOD16A2 evapotranspiration product in an irrigation district of Southern Italy. Agricultural Water Management. 167, 86-94.

Ayyoub, A., Khabba, S, Er-Raki, S., Merlin, O., Bahlaoui. (2017). A. Calibration and validation of the Penman-Monteith Model for estimating evapotranspiration of an orange orchard in semi-arid region, accepted. Acta Horticulturae. 1150, 15-22. 
A. Ayyoub, S. Er-Raki, S. Khabba, O. Merlin, J. Ezzahar, J.C. Rodriguez, A. Bahlaoui, A. Chehbouni, A simple and alternative approach based on reference evapotranspiration and leaf area index for estimating tree transpiration in semi-arid regions, Agricultural Water Management, Volume 188, 2017, Pages 61-68, ISSN 0378-3774, http://dx.doi.org/10.1016/j.agwat.2017.04.005.

Baldocchi, D.D., Hicks, B.B., Meyers, T.P. (1988). Measuring biosphere-atmosphere exchanges of biologically related gases with micrometeorological methods. Ecology 69, 1331-1340.

Baldocchi D. (1994). A comparative study of mass and energy exchange over a closed (wheat) and an open (corn) canopy: I. The partitioning of available energy into latent and sensible heat exchange. Agricultural and Forest Meteorology. 67, 191-220.

Barbosa da Silva, B., and T.V. Ramana Rao. (2005). The CWSI variations of a cotton crop in a semi-arid region of Northeast Brazil. Journal of Arid Environments. 62, 649-659.

Belaqziz S., Mangiarotti S., Le Page M., Khabba S., Er-Raki S., Agouti T., Drapeau L., Kharrou M.H., El Adnani M., Jarlan L. 2014. Irrigation scheduling of a classical gravity network based on the Covariance Matrix Adaptation - Evolutionary Strategy algorithm. Computers and Electronics in Agriculture, 102: 64-72.

Belaqziz, S., Khabba, S., Er-Raki, S., Jarlan, L., Le Page, M.H., Kharrou, M., El Adnani, M., Chehbouni, A. (2013). A new irrigation priority index based on remote sensing data for assessing the networks irrigation scheduling. Agricultural Water Management. 119, 1-9.

Boulet, G., Chehbouni, A., Braud, I., Vauclin M., Haverkamp, R., Zammit, C. (2000). A simple water and energy balance model designed for specialization and remote sensing data utilization. Agricultural and Forest Meteorology. 105, 117-132.

Boulet, G., Olioso, A., Ceschia, E., Marloie, O.,Coudert, B. (2012). An empirical expression to relate aerodynamic and surface temperatures for use within single-source energy balance models. Agricultural and Forest Meteorology, Elsevier Masson. 161, 148-155.

Braud, I., Dantas-Antonino, A. C., Vaulcin, M., Throny, J. L and ruelle, P. (1995). A Simple Soil_Plant-Atmosphere Transfert model (SiSPAT), development and field verification. Journal of Hydrology. 166, 231-260. 
Brisson, N., Mary, B., Ripoche, D., Jeuffroy, M. H. (1998). STICS: ageneric model for the simulation of crops and their water and nitrogen balances. 1. Theory and parameterization applied to wheat and corn. Agronomie. 18, 311-346.

Brutsaert, W. (1975). On a derivable formula for long-wave radiation from clear skies. Water Resources Research. 11(5), 742-744.

Carlson T.N., Buffum M.J. (1989). On estimating total daily evapotranspiration from remote sensing surface temperature measurements. Remote Sensing of Environment. 29(2), 197207.

Daamen, C.C., Simmonds, L.P., Wallace, J.S., Laryea, K.B., Sivakumar, M.V.K. (1993). Use of microlysimeters to measure evaporation from sandy soils. Agricultural and Forest Meteorology. 65, 159-173.

Debnath, S., Adamala, S., Raghuwanshi, N.S. 2015. Sensitivity Analysis of FAO-56 PenmanMonteith Method for Different Agro-ecological Regions of India. Environmental Processes, 2 (4), pp. 689-704.

A. Diarra, L. Jarlan, S. Er-Raki, M. Le Page, G. Aouade, A. Tavernier, G. Boulet, J. Ezzahar, O. Merlin, S. Khabba, Performance of the two-source energy budget (TSEB) model for the monitoring of evapotranspiration over irrigated annual crops in North Africa, Agricultural Water Management, Volume 193, 2017, Pages 71-88, ISSN 0378-3774, http://dx.doi.org/10.1016/j.agwat.2017.08.007.

Edwards, W.R.N. (1986). Precision weighing lysimetry for trees, using a simplified tared-balance design. Tree Physiology. 1, 127-144.

Er-Raki, S., Ezzahar, J., Khabba, S., Jarlan, L., Kharrou, M.H., and Chehbouni, G. (2013). Micrometeorology Tools for Measuring Evapotranspiration from the Leaf to the Region. In: S. Er-Raki (Eds.), Evapotranspiration: Processes, Sources and Environmental Implications. Nova Publishers, ISBN: 978-1-62417-138-3. 1-22.

Er-Raki, S., Amazirh, A., Ayyoub, A., Khabba, S., Merlin, O., Ezzahar, J., Chehbouni, A. (2016). Integrating thermal surface temperature into Penman-Monteith model for estimating crop water stress and evapotranspiration of an orange orchad in semi-arid region. Acta Horticulturae journal, in press. 
Er-Raki, S., Rodriguez, J.C., Garatuza, J.P., Watts, C., Chehbouni, G. (2013). Determination of crop evapotranspiration of table grapes in a semi-arid region of Northwest Mexico using multi-spectral vegetation index. Agricultural Water Management.122, 12-19.

Er-Raki, S., Chehbouni, A., Hoedjes, J., Ezzahar, J., Duchemin, B., Jacob, F. (2008). Improvement of FAO-56 method for olive orchards through sequential assimilation of Thermal infrared based estimates of ET. Agricultural Water Management. 95, 309-321.

Er-Raki, S., Chehbouni, A., Guemouria, N., Duchemin, B., Ezzahar, J., Hadria, R. (2007). Combining FAO-56 model and ground-based remote sensing to estimate water consumptions of wheat crops in a semi-arid region. Agricultural Water Management. 87, 4154.

Er-Raki, S., Chehbouni, A., Guemouria, N., Ezzahar, J., Khabba, S., Boulet, G. and Hanich. L. (2009). Citrus orchard evapotranspiration: Comparison between eddy covariance measurements and the FAO 56 approach estimates. Plant Biosystems. 143 (1), 201-208.

Er-Raki, S., Chehbouni, A., Boulet, G., Williams, D.G. (2010). Using the dual approach of FAO56 for partitioning ET into soil and plant components for olive orchards in a semi-arid region. Agricultural Water Management. 97, 1769-1778.

Ezzahar J., Chehbouni A., Er-Raki S., and L. Hanich. (2009). Combining a Large Aperture Scintillometer and estimates of available energy to derive evapotranspiration over several agricultural fields in semi-arid regions. Plant Biosystems. 143, 209-221.

Ezzahar J. and Chehbouni A. (2009). The use of the scintillometry for validating the spatial and temporal aggregation schema over heterogeneous grid. Agricultural and Forest Meteorology. 149, 2098-2109.

Gentine, P., Entekhabi, D., Chehbouni, A., Boulet, G. and Duchemin, B. (2007). Analysis of evaporative fraction diurnal behaviour. Agricultural and Forest Meteorology. 143(1-2), 1329.

Granger R.J. (2000). Satellite-derived estimates of evapotranspiration in the Gediz Basin. Journal of Hydrology. 229, 70-76. 
Hadria, R. (2006). Adaptation et spatialisation du modèle de cultures STICS pour la gestion d'un périmètre céréalier irrigué en milieu semi-aride. Thèse de doctorat, Faculté des Sciences Semlalia, Marrakech, Maroc. 174.

Hatfield, J.L. (1983). Evapotranspiration Obtained from Remote Sensing Methods. Advances in Irrigation. 2, 395-416.

Jackson, R.D., Idso, S.B., Reginato, R.J. (1981). Canopy temperature as a crop water stress indicator. Water Resources Research. 17, 1133-1138.

Jarvis, P.G. (1976). The interpretation of the variations in leaf water potential and stomatal conductance found in canopies in the field. Philosophical Transactions pf the Royal Society. $273,593-610$.

Jin, X., Yang, G., Xue, X., Xu, X., Li, Z., Feng, H. 2017. Validation of two Huanjing-1A/B satellite-based FAO-56 models for estimating winter wheat crop evapotranspiration during mid-season. Agricultural Water Management, 189, pp. 27-38.

Kalma, J.D., McVicar, T.R., McCabe, M.F. Estimating land surface evaporation. (2008). A review of methods using remotely sensed surface temperature data. Surveys in Geophysics. 29, $421-469$.

Karrou, M. (2003). Conduite du blé au Maroc. INRA éditions, Rabat.

Katerji, N., Perrier, A. (1983). Modélisation de l'évapotranpsiration réelle ETR d'une parcelle de luzerne: Rôle d'un coefficient cultural. Agronomie. 3, 513-521.

Katerji, N., Hamdy, A., Raad, A., Mastrorilli, M. (1991). Conséquence d'une contrainte hydrique appliquée à différents stades phénologiques sur le rendement des plantes de poivron. Agronomie. 11, 679-687.

Katerji N. and Rana G. (2006). Modelling evapotranspiration of six irrigated crops under Mediterranean climate conditions. Agricultural and Forest Meteorology. 138, 142-155.

Kohsiek, W., Meijninger, W.M.L., Moene, A.F., Heusinkveld, B.G., Hartogensis, O.K.,Hillen, W.C.A.M., H.A.R. de Bruin. (2002). An extra large aperture scintillometer for long range application. Boundary Layer Meteorology. 105, 119-127. 
Kustas, W.P., Norman, J.M. (1996). Use of remote sensing for evapotranspiration monitoring over land surfaces. Hydrological Sciences Journal. 41, 495-516.

Li, Z.L., Tang, R., Wan, Z., Bi, Y., Zhou, C., Tang, B., Yan, G., Zhang, X. (2009). A review of current methodologies for regional evapotranspiration estimation from remotely sensed data. Sensors. 9, 3801-3853.

Menenti, M., Choudhury, B.J. (1993). Parameterization of land surface evaporation by means of location dependent potential evaporation and surface temperature range. Exchange processes at the land surface for a range of space and time scales, Yokohama, Japan, IAHS.

Merlin, O. (2013). An original interpretation of the wet edge of the surface temperature-albedo space to estimate crop evapotranspiration (SEB-1S), and its validation over an irrigated area in northwestern Mexico. Hydrology and Earth System Sciences. 17, 3623-3637.

Merlin, O., Chirouze, J., Olioso, A., Jarlan, L., Chehbouni. A., Boulet, G. (2014). An image-based four-source surface energy balance model to estimate crop evapotranspiration from solar reflectance/thermal emission data (SEB-4S). Agricultural and Forest Meteorology. 184, $188-203$.

Merlin, O., Stefan, V. G., Amazirh, A., Chanzy, A., Ceschia, E., Er-Raki, S., \& Beringer, J. (2016). Modeling soil evaporation efficiency in a range of soil and atmospheric conditions using a meta-analysis approach. Water Resources Research. 52(5), 3663-3684.

Moran, M.S., Jackson, R.D. (1991). Assessing the spatial distribution of evapotranspiration using remotely sensed inputs. J. Journal of Environmental Quality. 20, 525-737.

Moran, M. S., Clarke T. R., Inoue, Y., Vidal, A. (1994). Estimating crop water deficit using the relation between surface-air temperature and spectral vegetation index. Remote Sensing of Environment. 49(3), 246-263.

Moran, M. S. (2004). Thermal in frared measurement as an indicator of ecosystem health. Thermal remote sensing in land surface processes. D. Quattrochi. CRC - Taylor \& Francis. 257-282.

Motisi, A., Consoli, S., Papa, R., Cammalleri, C., Rossi, F., Minacapilli, M., Rallo, G. 2012. Eddy covariance and sap flow measurement of energy and mass exchanges of woody crops in a Mediterranean environment. Acta Horticulturae, 951, pp. 121-128. 
Noilhan, J., Mahfouf, J.F. (1996). The ISBA land surface parameterisation scheme. Global and Planetary Change. 13, 145-159.

Olioso, A.; Mira, M., Courault, D., Marloie, O., Guillevic, P. (2013). Impact of surface emissivity and atmospheric conditions on surface temperatures estimated from top of canopy brightness temperatures derived from Landsat 7 data. In Proceedings of the 2013 IEEE International Geoscience and Remote Sensing Symposium, Melbourne, Australia. 3033-3036.

Philipp Drerup, Holger Brueck, Heinrich W. Scherer, Evapotranspiration of winter wheat estimated with the FAO 56 approach and NDVI measurements in a temperate humid climate of NW Europe, Agricultural Water Management, Volume 192, 2017, Pages 180-188, ISSN 0378-3774, http://dx.doi.org/10.1016/j.agwat.2017.07.010.

Prihodko, I., Goward, S. N. (1997). Estimation of air temperature from remotely sensed surface observations. Remote Sensing of Environment. 60(3), 335-346.

Raes, D., Steduto, P., Hsiao, T.C., Fereres, E., 2009. AquaCrop-the FAO crop modelto simulate yield response to water: II. Main algorithms and software description. Agronomy Journal. $101,438-447$.

Rallo, G., Baiamonte, G., Manzano Juárez, J., Provenzano, G. 2014. Improvement of FAO-56 model to estimate transpiration fluxes of drought tolerant crops under soil water deficit: Application for olive groves. Journal of Irrigation and Drainage Engineering, 140 (9), art. no. A4014001.

Rallo, G., González-Altozano, P., Manzano-Juárez, J., Provenzano, G. 2017. Using field measurements and FAO-56 model to assess the eco-physiological response of citrus orchards under regulated deficit irrigation. Agricultural Water Management, 180, pp. 136147.

Ramoelo, A., Majozi, N., Mathieu, R., Jovanovic, N., Nickless, A., Dzikiti, S., 2014.Validation of global evapotranspiration product (MOD16) using flux towerdata in the African savanna, South Africa. Remote Sens. 6 (8), 7406-7423.

Rana, G., Katerji, N., de Lorenzi, F. (2005). Measurement and modelling of evapotranspiration of irrigated citrus orchard under Mediterranean conditions. Agricultural and Forest Meteorology. 128, 199-209. 
Ray G. Anderson, Joseph G. Alfieri, Rebecca Tirado-Corbalá, Jim Gartung, Lynn G. McKee, John H. Prueger, Dong Wang, James E. Ayars, William P. Kustas, Assessing FAO-56 dual crop coefficients using eddy covariance flux partitioning, Agricultural Water Management, Volume 179, 2017, Pages 92-102, ISSN 0378-3774, http://dx.doi.org/10.1016/j.agwat.2016.07.027.

Ritchie, J.T. (1986). The CERES-Maize model. In: Jones, C.A., Kiniry, J.R. (Eds.), CERESMaize: Simulation Model of Maize Growth and Development. Texas A M University press, College Station, TX. 3-6.

Ruhoff, A.L., Paz, A.R., Aragao, L.E.O.C., Mu, Q., Malhi, Y., Collischonn, W., Rocha,H.R., Running, S.W., 2013. Assessment of the MODIS global evapotranspirationalgorithm using eddy covariance measurements and hydrological modelling inthe Rio Grande basin. Hydrol. Sci. J. 58, 1-19, http://dx.doi.org/10.1080/02626667.2013.837578.

Sandholt, I Rasmussen, K., Andersen. J. (2002). A simple interpretation of the temperature/vegetation index space for assessment of surface moisture status. Remote Sensing of Environment. 79(2-3), 213-224.

Stefan, V. G., Merlin, O., Er-Raki, S., Escorihuela, M. J., \& Khabba, S. (2015). Consistency between in situ, model-derived and high-resolution-image-based soil temperature endmembers: Towards a robust data-based model for multi-resolution monitoring of crop evapotranspiration. Remote Sensing. 7(8), 10444-10479.

Su, Z. (2002). The Surface Energy Balance (SEBS) for estimation of turbulent heat fluxes. Hydrology and Earth System Sciences. 6(1), 85-99.

Tardy, B., Rivalland, V., Huc, M., Olivier, H., Sebastien, M., Gilles, B. (2016). A Software Tool for Atmospheric Correction and Surface Temperature Estimation of Landsat Infrared Thermal Data. Remote Sensing. 1-24.

Scott, R.W.C., Garatuza-Payan, J., Edwards, E., Goodrich, D.C., Williams, D.G., Shuttleworth, W.J. (2003). The understory and overstory partitioning of energy and water fluxes in an open canopy, semi-arid woodland. Agricultural and Forest Meteorology. 114, 127-139.

Smith, D.M., Allen, S.J. (1996). Measurement of sap flow in plant stems. Journal of Experimental Botany. 47, 1833-1844. 
674 Testi L., Villalobos F.J., Orgaz F. (2004). Evapotranspiration of a young irrigated olive orchard in $675 \quad$ southern Spain. Agricultural and Forest Meteorology. 121, 1-18.

676 Wan, Z., Wang, P. \& LI, X. (2004): Using MODIS Land Surface Temperature and Normalized 677 Difference Vegetation Index products for monitoring drought in the southern Great Plains, $678 \quad$ USA. International Journal of Remote Sensing. 25(1), 61-72.

679 WANG, P.-X., LI, X.-W., GONG, J.-Y., and SONG, C.-H. 2001. Vegetation temperature 680 condition index and its application for drought monitoring. Proceedings of International 681 Geoscience and Remote Sensing Symposium, 9-14 July 2001, Sydney, Australia 682 (Piscataway, NJ: IEEE). 141-143.

683 Wang, C.Y., Qi, S.H., Niu, Z., Wang, J.B. (2004). Evaluating soil moisture status in China using 684 the temperature-vegetation dryness index (TVDI). Canadian Journal of Remote Sensing. 30 $685 \quad(5), 671-679$. 